\title{
Mixed Convection of Hybrid Nanofluids in an Annulus
}

\author{
F. Selimefendigil ${ }^{1}$, H. F. Öztop ${ }^{2}$, Mohamed E. $\mathrm{Ali}^{3}$ \\ 1. Department of Mechanical Engineering, Celal Bayar University, Manisa, Turkey \\ 2. Department of Mechanical Engineering, Technology Faculty, Firat University, Elazig, \\ Turkey \\ 3. Department of Mechanical Engineering, College of Engineering, King Saud University, \\ Riyadh, Saudi Arabia \\ E-mail:mali@ksu.edu.sa
}

Received: 11 October 2018; Accepted: 27 October 2018; Available online: 25 December 2018

\begin{abstract}
In this study, mixed convection in an annulus formed by two horizontal isothermal cylinder surfaces and filled with hybrid nanofluids was examined with Galerkin weighted residual finite element method. The outer cylinder is rotating and inner cylinder is stationary. Influence of Rayleigh number, angular rotational speed of the outer cylinder, eccentricity of the inner cylinder, solid volume fractions of different nanoparticles (alumina, copper, hybrid particles between 0 and 0.02 ) on the fluid flow and heat transfer characteristics were analyzed. It was observed that average heat transfer enhances with Rayleigh number, solid volume fractions of nanoparticles and eccentricity ratio and reduces as the angular rotational speed of the outer cylinder increases. Adding nanoparticles was found to be advantageous for lower values of Rayleigh number and higher values of angular rotational speed. At the highest volume fraction of $\mathrm{Cu}$ nanoparticles, average Nusselt number increases by $31.75 \%$ when the inner cylinder center moves in $+y$ direction. Nanofluid with hybrid nanoparticles gives heat transfer rates which are higher than that of with alumina and lower than that of with copper nanoparticles for the same volume fraction.

Keywords: Rotating Surfaces; Convection; Numerical Simulation
\end{abstract}

\section{Introduction}

Free convection within the annulus of horizontal cylinders was studied by many researchers due to its importance in various engineering applications such as thermal energy storage, solar power, heat exchangers and many others. A review of convective heat transfers and fluid flow was presented by Dawood et al. [1]. Rotating or moving walls can be used to effect the fluid flow and heat transfer characteristics [2-5]. An experimental study of natural convection in an annulus bounded by two isothermal surfaces was performed by Kuehn and Goldstein [6]. Influence of Rayleigh number, eccentricity on the heat transfer and fluid flow was investigated and different flow regimes were identified. Natural convection in the annulus of two isothermal cylinders were studied by Cho et al. [7] and effects of diameter ratio, eccentricity and azimuthal location of inner cylinder on the heat transfer enhancements were analyzed. Natural convection heat transfer can be enhanced with the use of nano-sized metallic or non-metallic particles within the base fluid. The thermal conductivity of nanoparticles is much higher than that of the traditional heat transfer fluids and they have the potential to enhance heat transfer as it is shown in various studies [8-27]. Size, shape and type of the nanoparticles are important in determining the rate of heat transfer enhancement. The pressure drop is little and convective heat transfer coefficient enhances much in heat exchangers when nanoparticles are added to the base fluid. Soleimani et al. [28] numerically examined the free convection in a semi annulus filled with $\mathrm{Cu}$-water nanofluid. The use of nanofluids was found to be effective especially for the low values of Rayleigh number. In a recent experimental study by de la Pena et al. [29], natural convection in a closed annular vertical enclosure filled with nano-oil was investigated. Various particle concentrations of AIN and $\mathrm{TiO} 2$ nanoparticles were used in oil with a high Prandtl number value. The rate of the heat transfer enhancements were observed only for certain conditions. In the numerical study by El-Maghlany and Elazm [30], mixed convection in an eccentric horizontal annulus filled with water and $\mathrm{Cu}, \mathrm{TiO} 2$ and $\mathrm{A} 12 \mathrm{O} 3$ nanoparticles were analyzed. The inner cylinder rotates and the two cylinder surfaces were kept at constant temperatures. They noted that use of nanoparticles is only effective for the mixed and natural convection regions. Mehrizi et al. [31] performed a numerical study of mixed convection in micro-annuli filled with electrically conductive nanofluids under the effect of magnetic field. They showed that taking into account the temperature dependent thermophysical properties does not change the flow fields and heat transfer behavior. Matin and Pop [32] performed 
numerical study of free convection in an eccentric horizontal annulus filled with copper-water nanofluid. Effects of Rayleigh number, eccentricity and nanoparticle volume fraction on the fluid flow and heat transfer were examined. A computational study by using Lattice Boltzmann method was performed for natural convection in a horizontal cylindrical annulus filled with nanofluids under the effect of magnetic field. As the nanoparticle solid volume fraction enhances, heat transfer was found to increase.

Recently, hybrid nanofluids which are prepared with hybrid nanoparticles are used in heat transfer applications [33-36]. Takabi et al. [34] gave a literature review for the preparation, thermal characteristics of the hybrid nanoparticles. In another review study, various properties and applications of hybrid nanofluids was given [35]. Due to the cost and stability issues, it may be necessary to take the advantage of one of the nanoparticles which results in preparation of hybrid nanofluids. With hybrid nanofluids it is also possible further heat transfer increment with enhanced thermal conductivity. Nimmagadda and Venkatasubbaiah [36] performed a numerical study of laminar forced convection in a micro-channel with aluminum oxide and silver hybrid nanoparticles. Effects of Reynolds number, hybrid nanoparticles volume concentration on the convective heat transfer coefficient were investigated. It was noted that the cost of working fluid reduces when higher volume concentrations of hybrid nanofluids were used. Kumar et al. [37] measured the thermal conductivity and viscosity of nanofluids with hybrid $\mathrm{Cu}-\mathrm{Zn}$ nanoparticles and various base fluids. It was observed that thermal conductivity is higher for vegetable oil whereas it is less stable. Minea [38] proposed numerical evaluation methods for the thermal conductivity and viscosity of nanofluids containing hybrid nanoparticles. They also proposed Nusselt number correlations for hybrid nanofluids. Thermophysical properties of nanofluids which are composed of diathermic oil and hybrid nanoparticles ( $\mathrm{SiC}$ - $\mathrm{TiO} 2)$ were determined. Nanoparticle concentration and temperature were found to enhance thermal conductivity of the nanofluid and the fluid could be regarded as Newtonian fluid.

Mixed convection in an eccentric annulus formed by two horizontal isothermal cylinder surfaces filled with hybrid nanofluids composed of alumina and cooper nanoparticles added to water was never studied in literature to the best of authors knowledge. The use of hybrid nanoparticles has the potential to control the convection inside the annulus with low cost. The study aims at investigating the heat transfer performance and fluid flow characteristics for various values of Rayleigh number, angular rotational speed of inner cylinder, eccentricity of the inner cylinder and hybrid nanoparticles volume fractions.

\section{Numerical modelling}

Annulus formed by two horizontal isothermal cylinder surfaces along with the boundary conditions are schematically shown in Figure 1 . The radii of the inner and outer cylinders are denoted by Ri and Ro with R0= 2.33Ri. The distance between the center of the inner and outer cylinders is e in y-direction. Eccentricity ratio is defined as $\mathrm{YR}=\mathrm{e} / \mathrm{Ri}$. The outer cylinder rotates with angular rotational speed of $\Omega$ while the inner cylinder is stationary. The inner and outer surfaces are kept at constant temperatures of $T_{h}$ and $T_{c}$, respectively with $T_{c}<T_{h}$. The annulus is filled with water and alumina, copper and hybrid nanoparticles at various volume concentrations. Thermo-physical properties of base fluid, alumina and copper particles are given in Table 1. The gravity acts in the negative y direction. Boussinesq approximation was used for the density variation for the buoyancy term. Laminar, steady and two-dimensional flow assumption was assumed in the annulus. Mass, momentum and energy conservation equations in a two-dimensional Cartesian coordinate system for the fluid within the annulus can be written as:

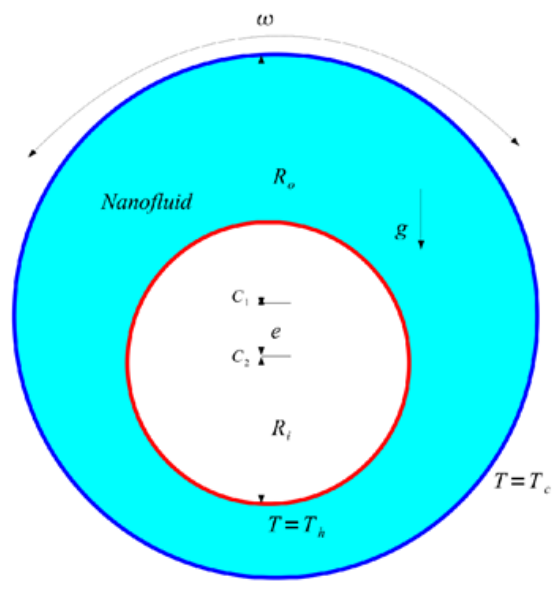

Figure 1. Schematic description of the physical model with boundary conditions 


$$
\begin{aligned}
& \nabla \cdot u=0 \\
& \rho_{f}(u) \cdot \nabla u=\nabla \cdot \sigma_{n f}+\rho_{n f} f^{b} \\
& u \nabla T=\alpha_{n f} \nabla^{2} T
\end{aligned}
$$

In the momentum equation, the buoyancy force, becomes:

$$
f_{\text {boun }}=\beta_{n f} g\left(T-T_{c}\right)
$$

Dimensionless form of governing equations can be obtained by using the following dimensionless parameters:

$$
\begin{aligned}
\mathrm{X} & =\frac{x}{D_{h}}, \quad \mathrm{Y}=\frac{y}{D_{h}}, \quad \mathrm{U}=\frac{u D_{h}}{\alpha}, \mathrm{V}=\frac{v D_{h}}{\alpha}, \mathrm{P}=\frac{p}{\rho\left(\alpha / D_{h}\right)^{2}} \\
\theta & =\frac{T-T_{c}}{T_{h}-T_{c}}, \quad \mathrm{Ra}=\frac{g \beta\left(T_{h}-T_{c}\right) D_{h}{ }^{3}}{\alpha v}, \quad \operatorname{Pr}=\frac{v}{\alpha}, \quad \operatorname{Re}=\frac{\omega D_{h}{ }^{2}}{v}, \quad \Omega=\frac{\omega D_{h}{ }^{2}}{\alpha}
\end{aligned}
$$

Effective thermo-physical properties of hybrid nanofluid can be given by the following expressions [34]:

$$
\begin{gathered}
\rho_{n f}=\varphi_{1} \rho_{1}+\varphi_{2} \rho_{2}+(1-\varphi) \rho_{f} \\
c_{p, n f}=\frac{\varphi_{1} \rho_{1} c_{p 1}+\varphi_{2} \rho_{2} c_{p 2}+(1-\varphi) \rho_{f} c_{p, f}}{\rho_{n f}} \\
\beta_{p, n f}=\frac{\varphi_{1} \rho_{1} \beta_{p 1}+\varphi_{2} \rho_{2} \beta_{p 2}+(1-\varphi) \rho_{f} \beta_{p, f}}{\rho_{n f}}
\end{gathered}
$$

where $\varphi$ denotes the overall solid volume concentration of the nanoparticles. Thermal conductivity of the hybrid nanofluid was defined according to Maxwell's model and it can be given as [34]:

$$
\frac{k_{n f}}{k_{f}}=\left(\frac{\varphi_{1} k_{1}+\varphi_{2} k_{2}}{\varphi}+2 k_{f}+2\left(\varphi_{1} k_{1}+\varphi_{2} k_{2}\right)-2 \varphi k_{f}\right) x\left(\frac{\varphi_{1} k_{1}+\varphi_{2} k_{2}}{\varphi}+2 k_{f}-\left(\varphi_{1} k_{1}+\varphi_{2} k_{2}\right)+\varphi k_{f}\right)^{-1}
$$

Brinkman model was used to define the dynamic viscosity of the nanofluid [34]:

$$
\mu_{n f}=\frac{\mu_{f}}{(1-\phi)^{2.5}}
$$

Dimensional boundary conditions can be expressed as follows:

For the inner surface, $u=v=0, T=T_{h}$

For the outer surface, $u=-\omega\left(x-x_{0}\right), \quad v=\omega\left(y-y_{0}\right), \quad T=T_{c}$

Local and average heat transfer are calculated as:

$$
N u_{s}=-\frac{k_{n f}}{k_{f}}\left(\frac{\partial \theta}{\partial n}\right), \quad N u_{m}=\frac{1}{2 \pi} \int_{0}^{\pi} N u_{s} d s
$$

Table 1. Thermophysical properties

\begin{tabular}{cccc}
\hline Property & Water & $\mathbf{A l}_{2} \mathbf{O}_{3}$ & $\mathbf{C u}$ \\
\hline$\rho\left(\mathrm{kg} \mathrm{m}^{-3)}\right.$ & 997.1 & 3970 & 8933 \\
$c_{p}\left(\mathrm{~J} \mathrm{~kg}^{-1} \mathrm{~K}^{-1}\right)$ & 4179 & 765 & 385 \\
$k\left(\mathrm{~W} \mathrm{~m}^{-1} \mathrm{~K}^{-1}\right)$ & 0.6 & 40 & 401 \\
$\beta\left(\mathrm{K}^{-1}\right)$ & $2.1 \times 10^{-4}$ & $0.9 \times 10^{-5}$ & $1.4 \times 10^{-5}$ \\
\hline
\end{tabular}

\section{Solution methodology}

Galerkin weighted residual finite element method was used for the solution of the governing equations. Interpolation functions were used for the approximation of the flow variables in the finite elements of the computational domain. When the approximated field variables are inserted into the governing equations, it will 
result in residual $\boldsymbol{R}$ and the weighted average of this residual will be forced to be zero over the computational domain as:

$$
\int_{\Omega} w_{k} R d v=0
$$

where $w_{k}$ denotes the weight function. The weight function is chosen from the same set of functions as of the trial functions in the Galerkin method. The resulting system of nonlinear ordinary differential equations were solved by using Newton-Raphson method. Numerical experiments with different grid sizes were performed to obtain a grid independence study. The results of average Nusselt number along the hot wall for various grid sizes at the highest values of parameters of interest are demonstrated in Table 2 ( $\mathrm{YR}=0, \mathrm{Ra}=10^{6}, \Omega=1000, \varphi=0.02, \mathrm{Cu}$ nanoparticles). Grid G5 with 39012 number of triangular elements was chosen.

The numerical results of Yoo [39] was chosen to validate the present solver. The outer cylinder surface is kept at constant cold temperature and rotates while the inner surface is stationary and kept at constant hot temperature. The comparison of the streamlines and isotherms for two different Reynolds number based on the rotational velocity of the outer cylinder are shown in Figure 2. The existing results of [40] was used to validate the present code further. Table 3 presents the comparison results of average Nusselt number at the top wall of a lid-driven cavity computed with the present solver and computed in ref. [40].

Table 2. Grid independence study for the highest values of parameters of interest ( $\left.\mathrm{YR}=0, \mathrm{Ra}=10^{6}, \Omega=1000\right)$

\begin{tabular}{ccc}
\hline Grid name & Number of elements & Average Nusselt number \\
\hline G1 & 960 & 7.380 \\
G2 & 2646 & 7.468 \\
G3 & 5178 & 7.946 \\
G5 & 20010 & 8.611 \\
G6 & 39012 & 8.998 \\
\hline
\end{tabular}

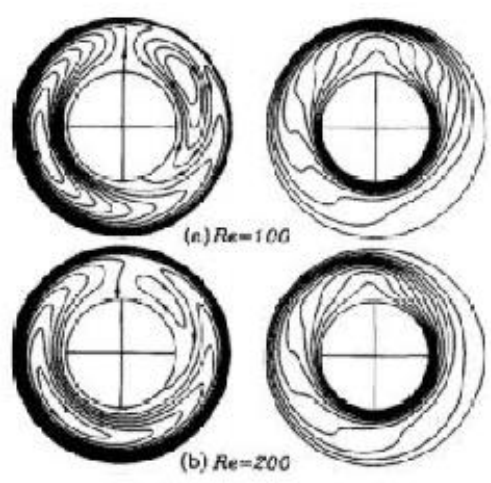

(a-b) numerical results of Yoo [39], left: streamlines, right: isotherms

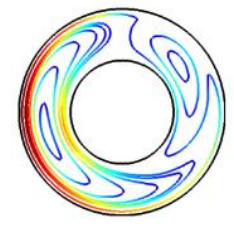

(c) $\mathrm{Re}=100$, stream

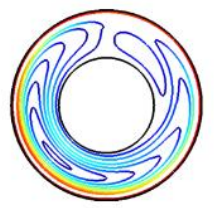

(e) $\mathrm{Re}=200$, stream

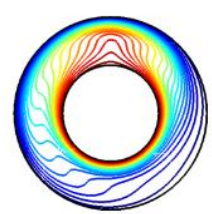

(d) $\mathrm{Re}=100$, isotherm

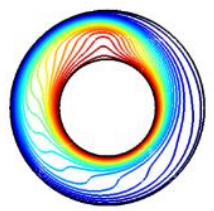

(f) $\mathrm{Re}=200$, temp

Figure 2. Verification of the numerical code with the results of Yoo [39], comparison of streamlines and isotherms 
Table 3. Comparison results of averaged Nusselt number at the top wall of the lid driven cavity

\begin{tabular}{ccc}
\hline $\mathbf{R e}=\mathbf{4 0 0}$ & Ref. [40] & Present \\
\hline $\mathrm{Gr}=100$ & 3.84 & 3.81 \\
$\mathrm{Gr}=10^{4}$ & 3.62 & 3.63 \\
$\mathrm{Gr}=10^{6}$ & 1.22 & 1.26 \\
\hline
\end{tabular}

\section{Results and discussion}

In this numerical simulation study, mixed convection of hybrid nanofluids in an annulus formed by two isothermal horizontal surfaces with the outer cylinder surface rotating is investigated. Effects of Rayleigh number (between $10^{4}$ and $10^{6}$ ), angular rotational speed of the outer cylinder (between 0 and 1000), eccentricity of the inner cylinder (between -0.2 and 0.2), solid nanoparticle volume fractions of different particles (alumina, copper, hybrid particles between 0 and 0.02) on the fluid flow and heat transfer characteristics were studied in detail. The base fluid Prandtl number is 7.1.

Streamline and isotherm distributions within the annulus for different values of Rayleigh number are demonstrated in Figure $3(\Omega=400, \mathrm{YR}=0, \varphi=0.01)$. The outer cylinder rotates in counter-clockwise rotation. For lower value of Rayleigh number, conduction mode of heat transfer is effective. The annulus is filled with a single recirculating cell and fluid velocity is higher near the outer rotating cylinder. As the value of Rayleigh number increases, natural convection effects become important and two vortices are formed in the left and right part of the annulus. Due to the rotation of the outer cylinder, the flow and thermal fields are not symmetric with respect to vertical axis. At the highest value of Rayleigh number, the number of vortices becomes three. Along the hot inner surface, isotherms become denser as the Rayleigh number enhances which is due to the increased effect natural convection. Only near the top part of the inner hot surface, temperate gradients are less steep which denotes the ineffective heat transfer locations. In the interior of the annulus, wavy thermal patterns are seen due to the enhanced natural convection. Richardson denotes the ratio of natural convection to the forced convection due to the outer rotating cylinder $\left(\mathrm{Ri}=\mathrm{Gr} / \mathrm{Re}^{2}\right)$. For this angular rotational speed of the cylinder $(\Omega=400)$, the range of Richardson number varies between 1.415 to 141.5 when Rayleigh number changes from $10^{4}$ to $10^{6}$. Variation of local and average Nusselt number along the hot wall for various Rayleigh number and solid particle volume fractions are shown in Figure 4. Except for the location near the upper part of the inner surface, heat transfer is locally enhanced for higher values of Rayleigh number. As the value of solid particle volume fraction increases, heat transfer is locally enhanced and it is more effective in the location where higher local heat transfer is achieved. Average heat transfer is higher for nanofluid with $\mathrm{Cu}$ particle and lowest for the nanofluid with alumina nanoparticles. The discrepancy between average Nusselt number for different nanoparticles is higher for higher values of Rayleigh number. Average Nusselt number enhances by about 5.804\%, 6.026\% and 6.058\% when nanofluids with alumina, hybrid and copper nanoparticles were used at the highest volume fraction for Rayleigh number of 104 . When the cylinders are stationary, for the lower values of Rayleigh number when conduction is dominant heat transfer mechanism, ratio of the average heat transfer rates for the case nanofluid and with base fluid is proportional to the conductivity ratio. Conductivity ratio enhances by about $6.105 \%, 6.070 \%$ and $5.844 \%$ for the nanofluid with copper, hybrid and alumina nanoparticles at the highest volume fraction $(\varphi=0.02)$ and therefore heat transfer enhances by the same amount for the conduction dominated case. At Rayleigh number of $10^{6}$, average Nusselt number increases by about $2.669 \%, 3.272 \%$ and $3.692 \%$ for the nanofluid with the alumina, hybrid and copper nanoparticles at volume fraction of $\varphi=0.02$. Adding nanoparticles is advantageous for the lower values of Rayleigh number when conduction is dominant.

Effects of varying angular rotational speed of the outer cylinder on the streamline and isotherm distributions within the annulus are shown in Figure $5\left(\mathrm{Ra}=10^{5}, \mathrm{YR}=0, \varphi=0.01\right)$. Richardson number values are 9.057 and 2.26 for angular rotational speed of 500 and 1000 . For the motionless cylinder, the annulus is occupied with two vortices and the flow and thermal field is symmetric with respect to vertical axis. As the outer cylinder rotates faster in the counter-clockwise direction, the vortices in the right part of the annulus disappears which is due to the forced convection contribution induced by rotation. Isotherm density enhances along the hot inner surface for lower values of angular rotational speed of outer cylinder. For the highest value of $\Omega$, isotherms are less clustered in the left part of the hot inner surface and heat transfer process is less effective in this location.

Local Nusselt number are significantly affected with outer cylinder rotations and as the value of increases, local heat transfer becomes less effective for the largest portion of the inner surface. Adding hybrid nanoparticles to the base fluid results in local heat transfer enhancement and its values are higher than alumina nanoparticles for the same volume fraction. Table 4 shows the variation of average Nusselt number for various values of solid particle volume fractions and $\Omega$. Average Nusselt number reduces by about $47.41 \%$ when increases from 0 to 1000 for the nanofluid with hybrid nanoparticles. Higher solid particle volume fractions result in heat transfer enhancement. For the stationary outer cylinder $(\Omega=0)$, average Nusselt number increases by about $2.316 \%, 3.505 \%$ and $2.981 \%$ 
for the nanofluid with alumina, copper and hybrid nanoparticles at the highest volume fraction. For cylinder angular rotational speed of $\Omega=1000,3.877 \%, 4.113 \%$ and $3.994 \%$ enhancements in the average heat transfer are achieved for nanofluids with alumina, copper and hybrid particles at the highest volume fraction. Adding nanoparticles is advantageous when average heat transfer rate is low which is the case when outer cylinder rotates.

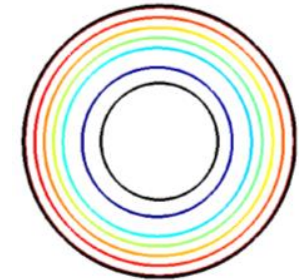

(a) $\mathrm{Ra}=10^{4}$

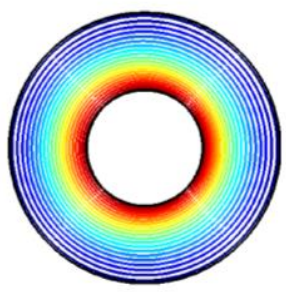

(d) $\mathrm{Ra}=10^{4}$

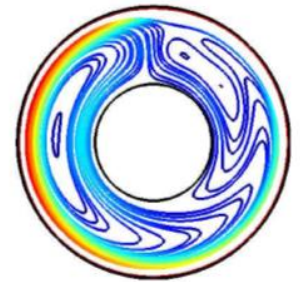

(b) $\mathrm{Ra}=10^{5}$

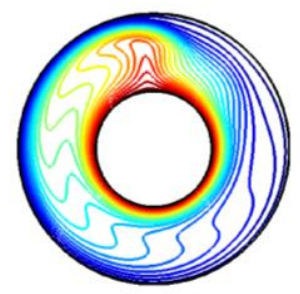

(e) $\mathrm{Ra}=10^{5}$

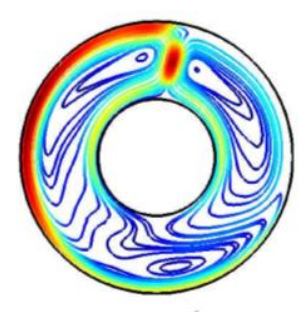

(c) $\operatorname{Ra}=10^{6}$

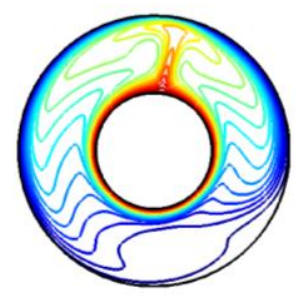

(f) $\mathrm{Ra}=10^{6}$

Figure 3. Variation of streamlines and isotherms within the annulus for different Rayleigh numbers $(\Omega=400$, $\mathrm{YR}=0, \varphi=0.01)$

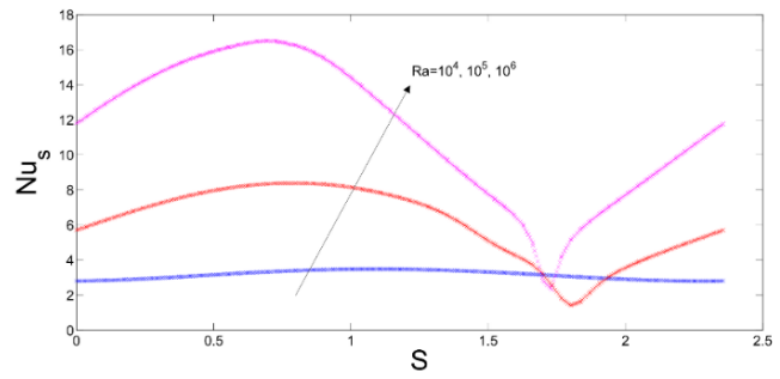

(a) local Nusselt number, $(\Omega=400, \phi=0)$

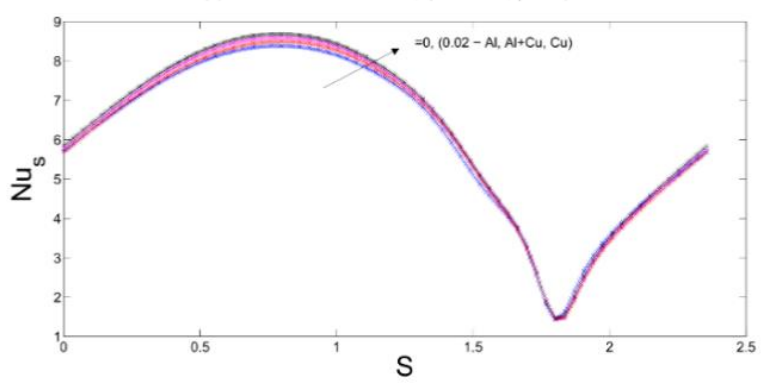

(b) local Nusselt number, $\left(\mathrm{Ra}=10^{5}, \Omega=400\right)$

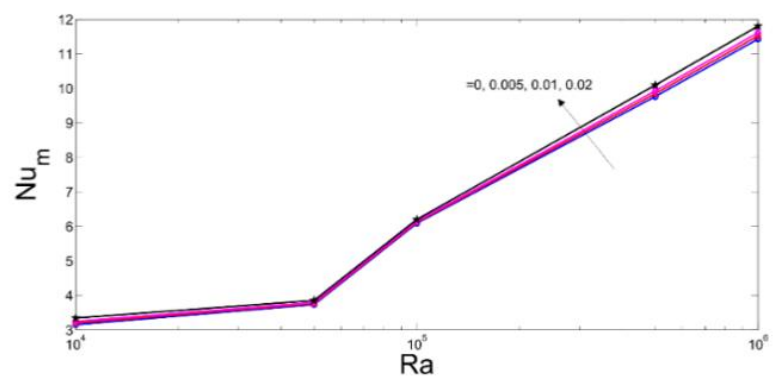

(c) averaged Nusselt number

Figure 4. Local Nusselt number distributions along the hot wall (a) for various Rayleigh numbers (b) for various solid particle volume fractions, (c) average Nusselt number for different nanoparticle volume fractions 


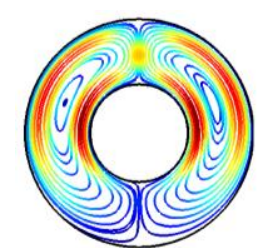

(a) $\Omega=0$

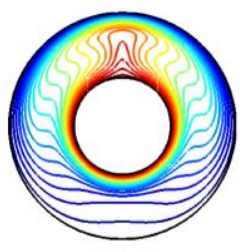

(d) $\Omega=0$

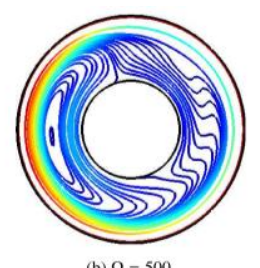

(b) $\Omega=500$

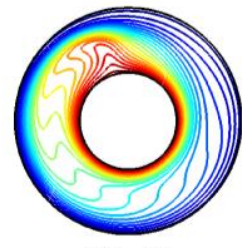

(e) $\Omega=500$

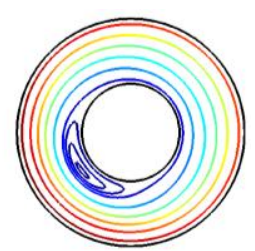

(c) $\Omega=1000$

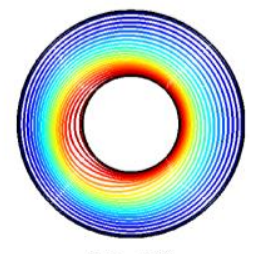

(f) $\Omega=1000$

Figure 5. Effects of varying angular rotational speed of outer cylinder on the streamline and isotherm distributions within the annulus ( $\mathrm{Ra}=10^{5}, \mathrm{YR}=0, \varphi=0.01$ )

Table 4. Effect of angular rotational speed of the outer cylinder on the average Nusselt number for different solid nanoparticle volume fraction $\left(\mathrm{Ra}=10^{5}, \mathrm{YR}=0\right)$

\begin{tabular}{ccccc}
\hline$\Omega$ & $\varphi$ & $\mathrm{Al}_{2} \mathrm{O}_{3}$ & $\mathrm{Cu}$ & $\mathrm{Cu}+\mathrm{Al}_{2} \mathrm{O}_{3}$ \\
\hline 0 & 0 & 6,475 & 6,475 & 6,475 \\
250 & 0 & 6,507 & 6,507 & 6,507 \\
500 & 0 & 5,2825 & 5,2825 & 5,2825 \\
750 & 0 & 4,034 & 4,034 & 4,034 \\
1000 & 0 & 3,405 & 3,405 & 3,405 \\
0 & 0,005 & 6,513 & 6,532 & 6,524 \\
250 & 0,005 & 6,54 & 6,56 & 6,551 \\
500 & 0,005 & 5,281 & 5,32 & 5,303 \\
750 & 0,005 & 4,046 & 4,062 & 4,055 \\
1000 & 0,005 & 3,436 & 3,438 & 3,437 \\
0 & 0,01 & 6,551 & 6,589 & 6,572 \\
250 & 0,01 & 6,571 & 6,612 & 6,594 \\
500 & 0,01 & 5,28 & 5,36 & 5,322 \\
750 & 0,01 & 4,057 & 4,089 & 4,075 \\
1000 & 0,01 & 3,468 & 3,472 & 3,472 \\
0 & 0,02 & 6,625 & 6,702 & 6,668 \\
250 & 0,02 & 6,631 & 6,714 & 6,677 \\
500 & 0,02 & 5,276 & 5,436 & 5,361 \\
750 & 0,02 & 4,08 & 4,141 & 4,114 \\
1000 & 0,02 & 3,537 & 3,545 & 3,545 \\
\hline & & & &
\end{tabular}

Figure 6 demonstrates the influence of eccentricity of the inner cylinder on the streamline and isotherm distributions $\left(\mathrm{Ra}=10^{5}, \Omega=500, \varphi=0.015\right.$, copper nanoparticles) for various eccentricity ratios. When the inner cylinder moves in $+y$ direction, the gap between the inner and outer cylinder surfaces reduces in the upper part. In the lower part of the annulus, the recirculation zone has a large influence region. When the inner cylinder moves in $-y$ direction, in the upper part of the annulus, two main recirculation zones are formed (Figure 6 (e)). The locations where steep temperature gradients are seen change when eccentricity of the inner cylinder changes. Average Nusselt number for various eccentricity ratios are tabulated in Table 5 for different particle types and two different volume fractions. When the inner cylinder moves in $+y$ and $-y$ directions, average heat transfer becomes effective and enhancement is higher for $+y$ direction. Percentage in the Nusselt number enhancements are $20.33 \%$ 
and $25.46 \%$ for nanofluid with alumina and copper nanoparticles at the highest volume fraction when the inner cylinder moves in $-\mathrm{y}$ direction $(\mathrm{YR}=-0.2)$. For the movement of inner cylinder in $+y$ direction, average heat transfer increases by about $31.75 \%$ for the nanofluid with copper particles at volume fraction of $\varphi=0.02$ cylinder moves in $-\mathrm{y}$ direction $(\mathrm{YR}=-0.2)$. For the movement of inner cylinder in $+\mathrm{y}$ direction, average heat transfer increases by about $31.75 \%$ for the nanofluid with copper particles at volume fraction of $\varphi=0.02$.

Table 5. Effect of eccentricity of the inner cylinder on the average Nusselt number for various particle types and solid volume fractions $\left(\mathrm{Ra}=10^{5}, \Omega=500\right)$

\begin{tabular}{ccccc}
\hline $\mathrm{YR}$ & $\varphi$ & $\mathrm{Al}_{2} \mathrm{O}_{3}$ & $\mathrm{Cu}$ & $\mathrm{Cu}+\mathrm{Al}_{2} \mathrm{O}_{3}$ \\
\hline $\mathbf{- 0 . 8 3 3}$ & 0.005 & 5.912 & 5.920 & 5.919 \\
$\mathbf{- 0 . 8 3 3}$ & 0.2 & 6.349 & 6.382 & 6.377 \\
$\mathbf{0}$ & 0.005 & 5.281 & 5.320 & 5.303 \\
$\mathbf{0}$ & 0.2 & 5.276 & 5.436 & 5.361 \\
$\mathbf{0 . 8 3 3}$ & 0.005 & 6.462 & 6.474 & 6.471 \\
$\mathbf{0 . 8 3 3}$ & 0.2 & 6.951 & 7.001 & 6.988 \\
\hline
\end{tabular}

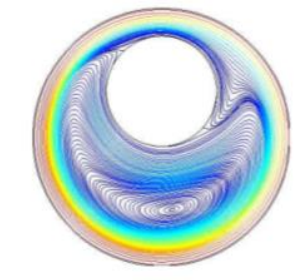

(a) $\mathrm{YR}=0.833$, streamline

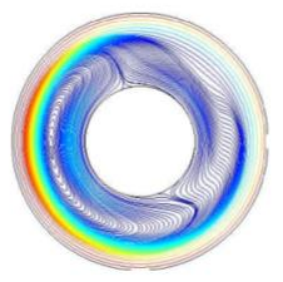

(c) $\mathrm{YR}=0$, streamline

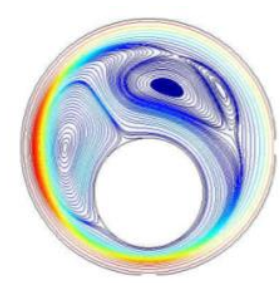

(e) $\mathrm{YR}=-0.833$, streamline

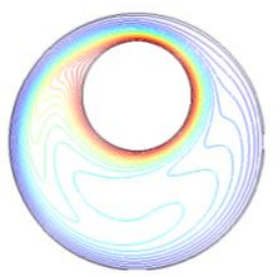

(b) $\mathrm{YR}=0.833$, isotherm

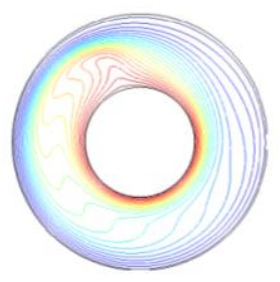

(d) $\mathrm{YR}=0$, isotherm

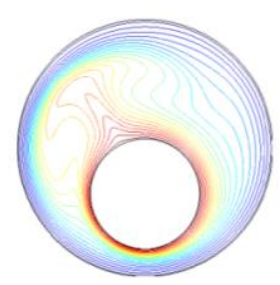

(f) $\mathrm{YR}=-0.833$, isotherm

Figure 6. Effects of eccentricity of the inner cylinder on the streamline and isotherm distributions within the annulus $\left(\mathrm{Ra}=10^{5}, \Omega=500, \varphi=0.015\right)$

\section{Concluding remarks}

Numerical simulation of mixed convection in a hybrid nanofluid filled annulus formed by two horizontal cylinders are studied. Outer cylinder rotates in counter-clockwise direction and kept at constant cold temperature while the inner cylinder is at constant hot temperature and remains stationary. Following conclusions can be drawn from the numerical simulation results as: 
1) Average Nusselt number enhances with Rayleigh number and deteriorates with angular rotational speed of the outer cylinder.

2) Adding nanoparticles are advantageous for lower values of Rayleigh number and higher values of angular rotational speed when average heat transfer is low. Nanofluids with hybrid nanoparticles gives higher heat transfer rates compared to alumina nanoparticles and gives lower heat transfer rates for copper nanoparticles.

3) Heat transfer enhancements are about $6 \%$ for the lowest value of Rayleigh number which are closer to the theoretical values when cylinders are stationary. Average Nusselt number reduces by about 47:41\% when angular rotational speed of the outer cylinder is increased from 0 to 1000.

4) Repositioning the inner cylinder in positive and negative y direction results in heat transfer enhancement and the effect is more pronounced for positive y movement of the inner cylinder center. At the highest volume fraction of $\mathrm{Cu}$ nanoparticles, average Nusselt number increases $31.75 \%$.

5) Finally polynomial type correlations for the average Nusselt number along the hot wall for various nanoparticle types are obtained which is third order in Rayleigh number and second order in angular rotational speed of the cylinder.

\section{Acknowledgment}

Second and third authors extend their appreciation to the International Scientific Partnership Program ISPP at King Saud University for funding this research work through ISPP\# 131.

\section{References}

[1] H. Dawood, H. Mohammed, N. A. C. Sidik, K. Munisamy, M. Wahid, Forced, natural and mixedconvection heat transfer and fluid flow in annulus: A review, International Communications in Heat and Mass Transfer 62 (2015) 45-57.

[2] M. A. Ismael, Numerical solution of mixed convection in a lid-driven cavity with arc-shaped moving wall, Engineering Computations 34 (2017) 869-891.

[3] F. Selimefendigil, M. A. Ismael, A. J. Chamkha, Mixed convection in superposed nanofluid and porous layers in square enclosure with inner rotating cylinder, International Journal of Mechanical Sciences 124- 125 (2017) 95108.

[4] F. Selimefendigil, H. F. Oztop, Mixed convection of nanofluids in a three dimensional cavity with two adiabatic inner rotating cylinders, International Journal of Heat and Mass Transfer 117 (2018) 331-343.

[5] F. Selimefendigil, H. F. Oztop, A. J. Chamkha, Fluidstructure-magnetic field interaction in a nanofluid filled lid-driven cavity with flexible side wall, European Journal of Mechanics - B/Fluids 61 (2017) 77-85.

[6] T. H. Kuehn, R. J. Goldstein, An experimental study of natural convection heat transfer in concentric and eccentric horizontal cylindrical annuli, J. Heat Transfer 100(4) (1978) 635-640.

[7] C. H. Cho, K. S. Chang, K. H. Park, Numerical simulation of natural convection in concentric and eccentric horizontal cylindrical annuli, J. Heat Transfer 104 (1982) 624-630.

[8] H. F. Oztop, E. Abu-Nada, Numerical study of natural convection in partially heated rectangular enclosures filled with nanofluids, International Journal of Heat and Fluid Flow 29 (2008) 1326-1336.

[9] W. Arshad, H. M. Ali, Graphene nanoplatelets nanofluids thermal and hydrodynamic performance on integral fin heat sink, International Journal of Heat and Mass Transfer 107 (2017) 995-1001.

[10] S. Kakac, A. Pramuanjaroenkij, Single-phase and two-phase treatments of convective heat transfer enhancement with nanofluids - a state-of-the-art review, International Journal of Thermal Sciences 100 (2016) 7597.

[11] K. Bashirnezhad, S. Bazri, M. R. Safaei, M. Goodarzi, M. Dahari, O. Mahian, A. S. Dalkilic, S.Wongwises, Viscosity of nanofluids: A review of recent experimental studies, International Communications in Heat and Mass Transfer, 73 (2016) 114-123.

[12] E. Abu-Nada, Z. Masoud, A. Hijazi, Natural convection heat transfer enhancement in horizontal concentric annuli using nanofluids, International Communications in Heat and Mass Transfer 35 (2008) 657-665.

[13] M. Goodarzi, M. Safaei, K. Vafai, G. Ahmadi, M. Dahari, S. Kazi, N. Jomhari, Investigation of nanofluid mixed convection in a shallow cavity using a two-phase mixture model, International Journal of Thermal Sciences 75 (2014) 204-220.

[14] F. Selimefendigil, H. F. Oztop, Pulsating nanofluids jet impingement cooling of a heated horizontal surface, International Journal of Heat and Mass Transfer 69 (2014) 54-65.

[15] W. Arshad, H. M. Ali, Experimental investigation of heat transfer and pressure drop in a straight minichannel heat sink using tio2 nanofluid, International Journal of Heat and Mass Transfer 110 (2017) 248-256.

[16] F. Selimefendigil, H. F. Oztop, Numerical study of mhd mixed convection in a nanofluid filled lid driven square enclosure with a rotating cylinder, International Journal of Heat and Mass Transfer 78 (2014) 741-754. 
[17] M. Goodarzi, A. Amiri, M. S. Goodarzi, M. R. Safaei, A. Karimipour, E. M. Languri, M. Dahari, Investigation of heat transfer and pressure drop of a counter flow corrugated plate heat exchanger using mwcnt based nanofluids, International Communications in Heat and Mass Transfer 66 (2015) 172-179.

[18] H. M. Ali,W. Arshad, Effect of channel angle of pin-fin heat sink on heat transfer performance using water based graphene nanoplatelets nanofluids, International Journal of Heat and Mass Transfer 106 (2017) 465-472.

[19] F. Selimefendigil, H. F. Oztop, Identification of forced convection in pulsating flow at a backward facing step with a stationary cylinder subjected to nanofluid, International Communications in Heat and Mass Transfer 45 (2013) 111-121.

[20] F. Selimefendigil, H. F. Oztop, Natural convection and entropy generation of nanofluid filled cavity having different shaped obstacles under the influence of magnetic field and internal heat generation, Journal of the Taiwan Institute of Chemical Engineers 56 (2015) 42-56.

[21] S. K. Das, S. U. S. Choi, H. E. Patel, Heat transfer in nanofluids-a review, Heat Transfer Engineering 27 (2006) 3-19.

[22] V. Trisaksri, S. Wongwises, Critical review of heat transfer characteristics of nanofluids, Renewable and Sustainable Energy Reviews 11 (2007) 512523.

[23] M. Sheikholeslami, H. Ashorynejad, P. Rana, Lattice boltzmann simulation of nanofluid heat transfer enhancement and entropy generation, Journal of Molecular Liquids 214 (2016) 86-95.

[24] H. R. Goshayeshi, M. R. Safaei, M. Goodarzi, M. Dahari, Particle size and type effects on heat transfer enhancement of ferro-nanofluids in a pulsating heat pipe, Powder Technology 301 (2016) 1218-1226.

[25] O. A. Akbari, M. R. Safaei, M. Goodarzi, N. S. Akbar, M. Zarringhalam, G. A. S. Shabani, M. Dahari, A modified two-phase mixture model of nanofluid flow and heat transfer in a 3-d curved microtube, Advanced Powder Technology 27 (2016) 2175-2185.

[26] S. A. Jajja, W. Ali, H. M. Ali, A. M. Ali, Water cooled minichannel heat sinks for microprocessor cooling:Effect of fin spacing, Applied Thermal Engineering 64 (2014) 76-82.

[27] H. M. Ali, H. Ali, H. Liaquat, H. T. B. Maqsood, M. A. Nadir, Experimental investigation of convective heat transfer augmentation for car radiator using zno-water nanofluids, Energy 84 (2015) 317-324.

[28] S. Soleimani, M. Sheikholeslami, D. Ganji, M. Gorji-Bandpay, Natural convection heat transfer in a nanofluid filled semi-annulus enclosure, International Communications in Heat and Mass Transfer 39 (2012) $565-574$.

[29] N. L. C. de la Pena, C. I. Rivera-Solorio, L. A. Payan-Rodriguez, A. J. Garcia-Cuellar, J. L. Lopez-Salinas, Experimental analysis of natural convection in vertical annuli filled with aln and tio2/mineral oil-based nanofluids, International Journal of Thermal Sciences 111 (2017) 138-145.

[30] W. M. El-Maghlany, M. M. A. Elazm, Influence of nanoparticles on mixed convection heat transfer in an eccentric horizontal annulus with rotating inner cylinder, Journal of the Taiwan Institute of Chemical Engineers 63 (2016) 259-270.

[31] A. A. Mehrizi, M. Farhadi, S. Shayamehr, Natural convection flow of cu-water nanofluid in horizontal cylindrical annuli with inner triangular cylinder using lattice boltzmann method, International Communications in Heat and Mass Transfer 44 (2013) 147-156.

[32] M. H. Matin, I. Pop, Natural convection flow and heat transfer in an eccentric annulus filled by copper nanofluid, International Journal of Heat and Mass Transfer 61 (2013) 353-364.

[33] S. Suresh, K. Venkitaraj, P. Selvakumar, M. Chandrasekar, Effect of Al2O3Cu/water hybrid nanofluid in heat transfer, Experimental Thermal and Fluid Science 38 (2012) 54-60.

[34] B. Takabi, A. M. Gheitaghy, P. Tazraei, Hybrid water-based suspension of al2o3 and cu nanoparticles on laminar convection effectiveness, Journal of Thermophysics and Heat Transfer 30 (2016) 523-532.

[35] S. Kakac, A. Pramuanjaroenkij, Review of convective heat transfer enhancement with nanofluids, International Journal of Heat and Mass Transfer 52 (2009) 3187-3196.

[36] R. Nimmagadda, K. Venkatasubbaiah, Conjugate heat transfer analysis of micro-channel using novel hybrid nanofluids, European Journal of Mechanics - B/Fluids 52 (2015) 19-27.

[37] M. S. Kumar, V. Vasu, A. V. Gopal, Thermal conductivity and rheological studies for cu-zn hybrid nanofluids with various basefluids, Journal of the Taiwan Institute of Chemical Engineers 66 (2016) 321-327.

[38] A. A. Minea, Hybrid nanofluids based on al2o3, tio2 and sio2: Numerical evaluation of different approaches, International Journal of Heat and Mass Transfer 104 (2017) 852-860.

[39] J. S. Yoo, Mixed convection of air between two horizontal concentric cylinders with a cooled rotating outer cylinder, Inf. J. Heat Maw Transfer 41 (1998) 293-302.

[40] R. Iwatsu, J. Hyun, K. Kuwahara, Mixed convection in a driven cavity with a stable vertical temperature gradient, Int. J. Heat Mass Transfer 36 (1993) 1601-1608.

(C) 2018 by the author(s). This work is licensed under a Creative Commons Attribution 4.0 International License (http://creativecommons.org/licenses/by/4.0/). Authors retain copyright of their work, with first publication rights granted to Tech Reviews Ltd. 